УДК 94(4)"1892"

UDC

DOI: $10.17223 / 23451734 / 6 / 3$

\title{
К ЧИТАТЕЛЮ
}

\section{А.С. Будилович}

\section{Резюме}

Статья является обращением главного редактора журнала «Славянское обозрение» А.С. Будиловича к читателям. Журнал выходил в Санкт-Петербурге в 1892 г. Во всех 18 выпусках Будилович в своих обращениях к читателям затрагивал актуальные вопросы славянской жизни.

Ключевые слова: А.С. Будилович, славяне, поляки, сербы, венгры, румыны, русины, Австро-Венгрия.

\section{TO THE READER}

\section{A.S. Budilovich}

\section{Abstract}

The article appears as an address to the readers from A.S. Budilovich, the chief editor of the Journal "Slavic Review". The journal was published in 1892 in St.Petersburg. In all 18 editions the address "To the Reader" was in regard to the actual questions of Slavic life.

Keywords: A.S. Budilovich, Slavs, Poles, Serbs, Hungarians, Romanians, Rusins, Austro-Hungary.

С тех пор как прекратилась публицистическая деятельность И.С. Аксакова, соединявшего несокрушимую веру в Россию и славянство с деятельным сознанием опасности их нынешнего положения, в нашей печати, по крайней мере, в большинстве изданий национального направления, постепенно установился довольно оптимистический взгляд на современный ход славянских дел.

Если бы оптимизм этот ограничивался лишь словами, то мы могли бы не придавать ему важного значения. Ведь есть народы, даже столь великие, как французский и китайский, которые искони привыкли к подобного рода самовозвышению: оно не подорвало, од- 
нако, мировой роли этих народов на протяжении многих веков их исторической жизни. Но мы - народ более искренний, прямолинейный, не привыкший строго отделять слов от дел. Если мы усвоили себе взгляд, что находимся в хорошем, чуть не нормальном положении, то не станем заботиться об его улучшении. Но что, если мы при этом ошибаемся, если вернее понимал нынешнее положение России и славян И. С. Аксаков, умерший, как известно, от боли сердца и с грустным предсказанием: «а гроза близится!»... Тогда наш оптимизм окажется не теоретической лишь ошибкой, но и тяжким преступлением перед историей и грехом против своего народа, которому придется расплачиваться за нашу слепую беспечность.

В таком случае, при невозможности всегда уметить в «золотую середину», не предпочтительнее ли держаться противоположного, строгого, требовательного по отношению к себе, пожалуй, пессимистического воззрения, которое все же толкает к труду, к осторожности, к самоусовершенствованию. Ведь это-то мировоззрение соответствует и истинному духу христианства, а не фарисейское самовозвышение оптимистов.

Присматриваясь в этих видах и с этими оговорками к нынешнему положению греко-славянского мира, мы вовсе не находим в нем оснований для оптимизма. Наоборот, положение это представляется нам крайне неопределенным, шатким, а иногда прямо опасным для нашей народной и культурной будущности.

Россия, например, при всем величии своей государственной области, даровитости и мощи своего стомиллионного населения и крепости своего политического строя все-таки не занимает теперь такого господствующего международного положения, как при Николае I, Александре I, быть может, и при Екатерине II, особенно на Балканском полуострове. Она вынуждена была в последнее время уступить там многие важные позиции Австро-Угрии и ее союзникам, напр. Боснию, Герцеговину, Болгарию. Даже Румыния явственно наклоняется теперь к антирусской лиге, которая из тройственной могла бы, при нашем бездействии, вновь разрастись до «двадесяти язык». Правда, русско-французская контрлига значительно улучшила наше международное положение; но и это улучшение могло бы быть вновь парализовано расширением среднеевропейской лиги на оставшиеся еще в стороне от нее государства. Это отчасти и сделано уже привлечением Швейцарии и Бельгии к среднеевропейскому торговому союзу, который существенно дополняет и расширяет прежний союз политический. Наконец, нынешнее равновесие коализованных европейских сил каждую минуту может быть нару- 
шено вмешательством Великобритании, которая, собственно, и теперь принадлежит нравственно, если не формально, к лиге австроитало-германской.

Но все же в отношении политическом Россия занимает, бесспорно, высшее место в ряду европейских государств, чем в отношениях общественном и экономическом. В сравнении с любым западноевропейским обществом русское осталось далеко позади по неумению организоваться, слабости личного и общественного почина, по застарелой привычке все сваливать на плечи государства. Сословные притязания не имеют, конечно, у нас той исторической почвы, следовательно, и силы, как на Западе; но тем произвольнее и вреднее они в своих проявлениях, особенно в областях окраинных, со смешанным населением. Шаткость нашего экономического благосостояния доказывается как возрастающей задолженностью, так и голодовками вроде нынешней печальнейшей, которая объясняется не одними ведь метеорологическими причинами. Это подтверждается и широким и до недавнего времени беспрепятственным распространением в России еврейства, которое уже само по себе служит указанием на ненормальность общественно-экономических условий русской жизни.

Мы по справедливости гордимся верностью русского народа не только духу, но и формам соборного христианства, религиозным заветам славянских первоучителей, вековым преданиям русско-славянской церкви. Но не видим ли одновременно и таких явлений, как штунда в народе, а пашковство, рэдстокизм, даже чуть-чуть не буддизм в воззрениях образованных классов русского общества?

Мы благополучно вышли, кажется, из периода продолжительной борьбы за классицизм и реализм. Но можем ли сказать, что успели установить лучший тип или типы русско-славянской высшей, средней и низшей школы в ее отношениях к государству и обществу, церкви и семье?

В области научно-литературной по многим ли предметам знания и родам творчества успела Россия занять подобающее себе место в ряду других великих народов и государств? Не представляется ли и теперь еще русский язык как бы подчиненным диалектом немецкого в изданиях некоторых наших ученых обществ и в преподавании некоторых балтийских школ?

III

При всем том по условиям своего развития Россия занимает теперь, бесспорно, самое лучшее положение из всех греко-славянских народов, особенно с тех пор, как в ней стало утверждаться народное направление во внешней и внутренней политике. 
Гораздо неблагоприятнее поставлены в этом отношении заграничные славяне. Возьмем, напр., наших червонорусских братьев. Разделенные в политическом отношении между Галичиной, Буковиной и Угрией, они осуждены вследствие того развиваться под чуждыми влияниями, а именно: первые под давлением поляков, вторые - немцев и румынов, третьи же - мадьяр. Лишь в лоне славянской церкви червонорусы могли бы найти опору для своих народных стремлений. Но и тут они весьма ослаблены вторжением в их храмы и монастыри то польских иезуитов и воскресенцев, то румынских пропагандистов, то мадьярских чиновников, при почти полной зависимости червонорусского духовенства от иноверного и иноплеменного правительства и патронов-помещиков, не говоря уже про собственных иерархов, которые назначаются по указаниям из Рима, Вены, Кракова, а не в духе народных желаний и требований. Доказательством тому может служить недавний львовский церковно-областной Синод, столь живо напоминающий по своему духу и приемам печальной памяти соборы Брестский и Замостский, казалось бы, давно отошедшие в область исторических воспоминаний наравне с павшей республикой. Столь же печально положение червонорусских школ, служащих не делу русской народности и человечности, а наоборот - полонизации русской молодежи в Галичине да онемечиванию или орумыниванию в Буковине и беспощадной мадьяризации в Угрии. Если прибавить к этому крайнее обеднение червонорусского населения вследствие высокого обложения, плохой администрации и высасывания евреями, то мы поймем причины постепенного вырождения этого населения в Галичине, как это доказано на цифрах польским экономистом Щепановским в сочинении Nędza Galicyi.

Скудная червонорусская литература, разделенная вдобавок на три части по областям и на множество разновидностей по произволу писателей, конечно, не может выдержать состязания даже с литературами польской, румынской и мадьярской, не говоря уже про возвышающуюся над всеми ими литературу общенемецкую. Лучшие силы червонорусского общества, весь подрост его учащейся молодежи должны постепенно отрываться от своих семейных, народных и церковных преданий и усиливать собой ряды противников Руси.

\section{IV}

Весьма неблагоприятно и нынешнее положение югославянских народов: болгарского, сербохорватского и словинского, из которых первый разделен в политическом отношении на три части, между Болгарией, Румынией и Турцией, второй - на шесть, между Сербией, Черногорией, Турцией, Новоавстрией (Босния с Герцеговиной), 
Цислейтанией и Транслейтанией, а третий - на три, между двумя последними и Италией. Но еще важнее то, что все эти народности охвачены теперь в большей или меньшей степени культурным воздействием латино-немецкого Запада, которому давно уже подчинились области словинские, наполовину - сербохорватские, а в новейшее время стали склоняться и болгарские. Это внесло рознь в среду югославян, возбудив хорватов против сербов почти в такой же мере, как поляков против русских. Если прибавить к этому старый антагонизм болгар к сербам, искусственно подогреваемый теперь из Вены и Будапешта ожесточенным спором из-за Македонии, который был одним из мотивов и злополучной войны 1885 г., то легко видеть, как глубоко расколот теперь славянский Юг, и как легко пользоваться этим расколом Западу.

Для нынешней истории югославян, особенно сербской при Милане и болгарской при Баттенберге и Кобурге, можно бы найти много аналогий в истории онемечения прибалтийских и полабских славян саксами, франками и другими наступательными немцами. Дай бог, чтобы окончательный исход борьбы за земли подбалканские и поддинарские не был столь же гибелен для славян, как на Лабе, Одре и Нижней Висле.

\section{$\mathrm{V}$}

Крайне тяжело и опасно нынешнее положение северо-западных славян, особенно словаков. Со времени введения дуализма они постепенно утратили всякое активное участие в политической жизни, так что не имеют теперь в угорском парламенте ни одного депутата, который хотя бы заявлял об их существовании. Занимая самые бедные, горные части Угрии, словаки и в экономическом отношении совершенно обессилены вымогательствами фискальными, так что лишь коробейничество да эмиграция в Америку еще поддерживают их от полного обеднения. И церковь не оказывает существенной поддержки этому в большинстве католическому, а в меньшинстве протестантскому народу, ибо через епископов и высший клир правительство наложило руку и на церковную автономию словаков, сделав, таким образом, церковь одним из орудий мадьяризации. Со времени насильственного закрытия трех частных словенских гимназий у словаков не осталось ни одной средней школы. В последнее же время и сельские училища, даже приюты для малолетков превращены в органы все того же насильственного мадьяризма.

Одна литература еще поддерживает народное сознание словаков; но при всей даровитости и самоотверженности словенских поэтов и публицистов все-таки борьба с литературой мадьярской, для которой работает и множество омадьяренных словаков, в конце концов должна будет оказаться неравной. 
$\mathrm{VI}$

Не особенно блестящим представляется и современное положение чехоморавян. Разделенные административно на три части (Чехия, Моравия, Силезия), они не могут действовать совместно в тяжелой борьбе с окружающими их немцами. Мы не удивляемся поэтому, что в недавней парламентской речи депутат Грегр назвал нынешнее положение чехов «вавилонским пленом» и сравнил его с положением жертвы «в пасти вампира».

Лучше социально-экономическое положение чехов, как это видно и из блестящего успеха недавней юбилейной выставки в Праге. Народ этот действительно занимает очень высокое место по способности к организации, по энергии и умелости труда, по бережливости и относительному благосостоянию. Но все это не может охранить и чехов от постепенного обеднения, если и впредь эта все же небольшая страна принуждена будет ежегодно выделять из своих заработков свыше 120 мил. (по расчету депутата Грегра) на Австрию. Уже и теперь в Чехии много бедного, безземельного, фабричного населения, которое изливается широким эмиграционным потоком то в Вену и другие части Австрии, то даже в Америку и отчасти в Россию.

В церковном отношении чехоморавяне не имеют самостоятельной организации, входя в состав латино-немецкой церкви, которая доныне не может простить чехам гуситства и потому всегда становится на сторону немцев в борьбе с чехоморавскими славянами.

В деле учебном последние поставлены гораздо лучше и словенцев, и словаков, и австрорусов, ибо имеют не только низшие и средние, но и высшие школы с народным языком. Это обстоятельство и поддерживает чехизм в его трудной борьбе с немцами при содействии очень живой публицистики и серьезной научной деятельности. Но если принять во внимание, что чехи ведут ее своими одиночными силами, австрийские же немцы опираются на язык и литературу всего немецкого племени, то нельзя не убедиться, что в конце концов и тут должны будут победить немцы, если не подоспеют на выручку чехов прочие ветви славянства.

\section{VII}

Нельзя назвать безопасным и нынешнего положения поляков. Уже сам факт их дробления между тремя столь различными по строю государствами, как Австрия, Германия и Россия, не представляется благоприятным для сохранения и развития этой народности как одного культурного целого. Наоборот, из нее должны постепенно выработаться три народа: австро-польский, германо-польский и русско-польский, с особыми бытовыми условиями, вкусами, иде- 
алами, особым мировоззрением. Латинская церковь является как бы общей головой этого рассеченного политически тела, причем ее влияние еще усиливается старым полутеократическим устройством польского общества. Но космополитический, во всяком же случае не славянский и не польский, а латинский характер этой церкви делает ее ненадежною опорою какой бы то ни было народности, следовательно, и польской. Особенно заметно это в Германии, где процесс онемечения поляков вовсе не сдерживается их католицизмом, как некогда это случилось и с прибалтийскими славянами, принадлежавшими главным образом к той же ляшской ветви славянства. Несколько лучше национальное положение поляков в Австрии; но оно привело их к другой опасности - полной изолированности между славянами и, как они думают, необходимости соединяться с его врагами - немцами, евреями, мадьярами. Лишь в России поляки не подвергаются ни тем опасностям, как в Германии, ни тем соблазнам, как в Австрии, потому что входят в состав государства славянского и притом громадного по пространству, следовательно, вовсе не нуждающегося в применении немецких способов вытеснения коренного населения из польского края. В этом смысле народную будущность русских поляков следует признать упроченной в гораздо большей степени, чем в онемечиваемой Познани или в юдаизуемой Галиции. Что же касается дальнейшего развития польской народности и польской образованности, то мы думаем, что оно могло бы совершаться под русским скипетром лишь в том случае, если бы эта образованность стала, наконец, развиваться параллельно с русской и прочими чисто славянскими, а не в противоположном, как доныне, направлении. Только в союзе с прочими славянскими языками и литературами может и польский язык устоять в неравной борьбе с немецким, который уже теперь господствует в Польше, Силезии, Пруссах, и который в самом сердце Польши имеет свои форпосты в виде немецких колонистов да онемеченных по разговорной речи евреев.

\section{VIII}

Остается еще упомянуть о крошечном полуторастатысячном народе - лужицких сербах. Как ни удивительна упорная живучесть этого консервативного народца, напоминающего пиренейских басков или британских кельтов, следует, однако, сознаться, что положение этого народа крайне опасно. Ни песчаные боры Верхних Лужиц, ни болотистые спревские леса Нижних не обезопашивают тех и других от натиска немцев. Если все-таки народ этот, разделенный вдобавок надвое и в политическом, и в церковном, и в диалектическом отношениях, устоит в неравной борьбе, то это будет чудом, 
вроде открытого недавно в горах Паропамиза остатка (точно ли?) греческих колонистов эпохи Александра Македонского!

Таким образом, славянство похоже теперь на связанного по рукам и ногам человека, на которого насели враги, открыли жилы и выпускают из них кровь, переливая ее, так сказать, в себя для обновления и укрепления своих жизненных сил.

\section{IX}

Но, рассуждая о современном славянстве в его отношениях к Западу, мы не можем, не должны забывать и тех неславянских народов, которые связаны с нашим племенем то по географической смежности, то по близости этнографической, по историческим преданиям, связям государственным, общественным, экономическим, церковным - вообще по принадлежности к общему греко-славянскому культурному типу. Между народами этими особенного внимания заслуживают летский и мадьярский на западе, румынский, греческий и турецкий на юге.

Вникая в условия нынешнего положения этих исторически связанных со славянством народов, мы замечаем, что и они переживают теперь критическую эпоху в своей истории.

Так, племя балтийское, или летское (латышско-литовское), расколотое в государственном отношении на две части, германскую и русскую, в обеих подвергается онемечению, хотя и в неравной мере. Быстрее совершается оно в Пруссах, которые из коренного края летского стали форпостом германизма на Востоке. Слабой опорой для летской народности служит латинская церковь. Наоборот, из истории известно, что она-то именно и была сильнейшим поборником германизации в землях Тевтонского и Ливонского орденов. Важнее в этом отношении для будущности летизма зародыши литературной деятельности на балтийских диалектах, особенно южнолитовском и латышском. Но доселе не выяснились еще вполне даже основные черты и стремления этой литературы, так что нельзя пока судить о том, станет ли она одной из диалектических литератур немецкой или русской язычной сферы, а, следовательно, явится ли она соратником восточной или западной образованности в дальнейшем их развитии.

\section{$X$}

Некоторые аналогии с народностью летской представляют и мадьяры, которые по вероисповеданию тоже относятся теперь к Западу, но по племенному типу, историческим преданиям и международному положению не отличаются существенно от смежных славянских народностей. В отношении политическом мадьяры по- 
ставлены гораздо выгоднее и летов, и большинства западных славян, ибо все входят в состав одного и притом довольно автономного государства, Угрии. Имея в своих руках и законодательство, и администрацию этой страны, ее суды, финансы, школы, мадьярский народ, по-видимому, мог бы с полным успехом развивать теперь все лучшие стороны и основы своего бытия. К сожалению, мы этого не видим. Вся деятельность мадьярской интеллигенции направлена в другую сторону: на насильственное утверждение мадьяризма на развалинах всех прочих народностей Угрии, причем и мысли нет о придании этому мадьяризму какого-нибудь высшего, культурного или вообще духовного значения. Это путь крайне опасный для народности столь малой и слабой, следовательно, столь зависимой от соседей, как мадьярская. Вызвав против себя единодушный ропот всех подавляемых народностей, мадьяры рискуют в один день потерять плоды своих многолетних усилий, как это предсказал недавно сам Кошут при обсуждении шансов войны, в которую могла бы быть вовлечена и Угрия. Что это предсказание может исполниться, доказывает история 1848-49 гг., когда мадьяризм потерпел полное крушение вследствие враждебного к нему отношения большинства угорских народов. Кому досталось бы в таком случае наследие Арпадовичей, немцам или славянам, это вопрос особый, очень трудный для решения. Но в обоих случаях очевидно, что мадьяры ставят теперь на карту все свое народное будущее.

В случае государственного кризиса положение мадьяризма было бы тем опаснее, что он не имеет собственно никакой внутренней опоры, ибо ни латинская, ни даже кальвинская церковь не может быть признана народно-мадьярской. Что касается экономических сил мадьярства, то они подрыты уже теперь еврейским землевладением, промышленностью, капиталами, подобно тому, как это замечается и в Галичине. Экономический упадок Угрии отражается и на возрастающем множестве эмигрантов, которые переносят в Новый Свет рабочие силы, не находящие производительного применения на родине.

Мадьярская наука и литература, питаемые соками, главным образом, омадьяренных славян, немцев, румынов, евреев, в отношении количественном очень значительны, быть может, превосходят любую из западнославянских литератур. Но так как мадьярская литература поддерживается, главным образом, ренегатами других народностей, то она не может, конечно, иметь идеального содержания и характера. С другой стороны, по направлению она все же находится в сильнейшей зависимости от немецкой, так что может даже рассматриваться как одна из диалектических подлитератур немецкого язычного круга, занимающая в их среде, быть может, первое место. 
Какие отсюда проистекают опасности для дальнейших судеб мадьяризма, для хода и исхода его многовековой борьбы с германизмом при замечаемом разрыве мадьяр со славянством, это легко видеть из вышесказанного.

\section{$\mathrm{XI}$}

На критическом распутье стоит теперь и румынская народность, благодаря, главным образом, государственному ее разделению на две части, молдо-валашскую и австро-угорскую. Первая могла бы с успехом развиваться в традиционном восточнохристианском направлении, если бы через Угрию, Семиградье, Буковину не проникали в нее теории и стремления совершенно противоположного, латино-немецкого происхождения. В прежнее время стремления эти были до некоторой степени поддерживаемы и панроманскими идеями, проникавшими из Франции, Испании, Италии. Теперь настроение романских стран, особенно Франции, существенно изменилось. Зато интересы Запада нашли себе в Румынии верного поборника в лице короля Карла Гогенцоллернского, который считает себя как бы новым гроссмейстером Тевтонского ордена на Нижнем Дунае.

Не менее вредит румынам их разделение на две церкви, православную и униатскую, из которых последняя довольно сильна в угро-румынских областях и служит как бы мостом для вторжения западных идей и в собственную Румынию. Этим главнейше путем вытеснены из последней кирилловские буквы, а с ними многие славяно-румынские слова, обороты, наконец, и старый полуславянский дух румынского общества и народа.

Утверждение в Семиградье и прочих угро-румынских областях мадьярских школ с колошварским университетом, а в Буковине школ немецких, с черновецким немецким университетом во главе является не менее важным фактором постепенного обезнароживания румынов в пользу то мадьяризма, то германизма. Это ослабляет, конечно, и значение румынской литературы, низводя ее постепенно до роли служебной в отношении не только к языку немецкому, но и мадьярскому.

\section{XII}

Переходя затем к грекам, мы видим, что интересы эллинизма в греческом королевстве охраняются, конечно, лучше, чем народные стремления большинства западных и южных славян, лишенных политической независимости. Но, с другой стороны, не нужно забывать, что королевство это не имеет еще ни национального, ни географического единства, след., необходимой полноты и цельности государственного организма. Особенно тягостно для новогреков 
господство Турции на о. Кандии, которая является вследствие того самым больным местом и Греции, и Турции. В некоторой мере то же относится и к другим турецким островам архипелага, который как древле, так и теперь должен считаться как бы национальной территорией греков. Не мешает отметить и то обстоятельство, что в среде населений новогреческого королевства довольно силен элемент инородческий, особенно албанский. Он открывает, правда, Греции как бы этнографическое право на Албанию, но, с другой стороны, ослабляет чистоту и цельность новогреческого племенного типа.

В отношении экономическом греки пользуются преимуществами народа мореходно-торгового. Но преимущества эти значительно ослабляются торговой конкуренцией «франков», особенно итальянцев, австрийцев и англичан, которые постепенно захватывают рынки Леванта, чтобы эксплуатировать их подобно своим колониям на материках черном, желтом и красном.

В религиозном отношении все почти греки принадлежат к одной и притом своей древней, национальной церкви. Но в отношении иерархическом они распадаются между несколькими автокефальными церквами, взаимные отношения которых нередко вызывают столкновение греков то с болгарами, то с арабами и другими христианскими народами Востока. Эти столкновения еще более обостряются заметным несоответствием великих исторических воспоминаний эллинизма с его нынешней скромной ролью на водах и побережьях Леванта. Это несоответствие придает несколько трагический характер панэллинской программе, окрещенной именем «великой идеи».

В отношении научно-литературном трудно ожидать для новогреков того значения, какое принадлежало некогда их отдаленным предкам в Ионии, Аттике, Великой Греции. Но было бы желательно, чтобы их знаменитый язык не был задавлен на Востоке языками итальянским, английским, немецким, которые заметно укрепляются в исконных гнездах древнегреческой и среднегреческой образованности.

\section{XIII}

Весьма тяжелый кризис переживается теперь и турецким народом. В течение многих веков он был носителем государства, обнимавшего лучшие части Старого Света и сыгравшего важную роль в истории средневековой и новой Европы. Но государство до такой степени поглощало внимание и силы этого народа, что их уже не хватило для развития прочих сторон образованности. Этим обусловлено было постепенное падение Турции и ее неспособность возродиться на новых началах. В этом и заключается главная причина ее болез- 
ней, которые вызвали целый ряд хирургических операций и довели ее теперь до роли одной из второстепенных держав, поддерживаемой главнейше взаимными антагонизмами и завистью между соседями. Дальнейшая судьба Турции зависит от того, сумеет ли она произвести добровольно размежевание своих областей с другими народами Востока или будет дожидаться вмешательства англичан и других франков, чтобы уплатить потом за него чем-нибудь вроде Боснии, Кипра, Египта.

\section{XIV}

Но если столь тяжело и даже опасно нынешнее положение славянских народностей и самой России со включением неславянских народов нашего круга, то в чем заключаются причины этого положения: в недостатке ли их сил? В перевесе ли сил противника? Едва ли в этом. Общая сумма всех этих народов достигает, без сомнения, полутораста миллионов человек, которые в смысле физическом смело могли бы помериться силами хотя бы с половиной Европы. Да и в духовном отношении племя, имеющее столь прочный политический базис, как Россия, скрепленная веками и обеспеченная несокрушимой твердостью нравственных связей Царя и Народа, племя, воспитанное в лоне греко-славянской церкви, усвоившее себе ее идеалы, проникнутое ее духом, связанное общими кирилло-мефодиевскими преданиями и заветами, к тому же племя молодое и даровитое, имеющее столь богатый и сильный язык, произведшее из своей среды не одного уже гения в области научно-литературной и художественной, не должно бы, кажется, бояться культурного соперничества более зрелых, но и утомленных уже жизнью народов Запада.

Почему же на деле видим противное, именно постепенное расширение западных народов и их образованности на территории и в среде народов христианского Востока?

По нашему убеждению, причина этого явления заключается, главным образом, в преимуществах западноевропейской организации сил, при полном их расстройстве и рассеянии в среде греко-славянской.

В самом деле, хотя наш культурный мир и не лишен нравственного средоточия и тяготения к нему, определяемого выдающимся положением в его системе русского народа, государства, общества, церкви, языка, однако степень этого тяготения ещё невелика по причине господства сил центробежных над центростремительными в психическом строе греко-славянских народов. Этим же объясняется слабость и взаимных связей между отдельными телами нашей племенной и культурной системы, а, следовательно, почти полное отсутствие их внутренней организации. 
При этом мы имеем в виду не столько политическую, сколько духовную организацию, ибо и на Западе бесспорное культурное единство народов романо-германских лишь в немногие исторические моменты (Карл Великий, Наполеон I) достигало и государственного объединения соответственных народов. Славян разделяют не столько политические грани, сколько антагонизмы другого, более внутреннего характера, например, между славянами православными и католическими, которые гораздо сильнее вероисповедной розни между католиками и протестантами на Западе или между суннитами и шиитами на Востоке.

В самом деле, вероисповедная рознь немцев не мешает им издавна чувствовать себя одним народом с общим языком, наукой, литературой, общими национальными и культурными задачами, чего нельзя сказать про взаимные отношения, например, русских к полякам или даже сербов к хорватам. Вся Германия, с включением немецкой Австрии, покрыта теперь бесчисленными немецкими национальными союзами: гимнастическими, певческими, школьными, научными, литературными, вообще культурными, которые имеют правильную организацию, общие съезды, центральные издания - словом, служат выражением и развитием идей национального единства немцев.

Ничего подобного не видим мы между славянами, даже в группах более тесных, например в западнославянской, в южнославянской и т. п.

Все немцы объединены теперь и в экономическом отношении новозаключенным торговым договором. Когда дождутся чего-нибудь подобного и народы греко-славянской системы?

А какой громадный перевес перед последними имеют немцы, французы, англичане и другие крупные западные народы в факте язычного их объединения! Правда, Россия имеет с прошлого века один общий язык; но за пределами ее все еще господствует такое смешение языков, какое было на Западе разве в средние века, до Лютера, Кальвина, Тиндаля. При таких условиях невозможен между народами нашей системы плодотворный обмен произведениями народной мысли и слова, а, следовательно, и их духовная солидарность, подобная существующей в широких размерах на Западе.

\section{$\mathrm{XV}$}

Без такого же обмена мыслей, без духовной взаимности грекославяне не могут даже приблизиться к решению многих основных вопросов своей национальной и культурной области. Таковы, например, вопрос русско-польский и примыкающий к нему малорусский или «русинский»; вопросы чешско-словенский, македонский, боснийский, греко-болгарский, цареградский, румынский, мадьярский и т. д., и т. д. 
Но над всеми этими частными вопросами возвышаются и требуют настоятельного разъяснения многие более общие вопросы нашего культурного мира, напр., о способах установления равновесия между центростремительными и центробежными силами в жизни народов нашего круга; об отношениях народности к культуре и задач племенных к общечеловеческим; об идеальных основах и практических путях религиозного их сближения; о лучшем типе грекославянской общественной организации; об идеалах нашей науки, литературы, искусства и средствах приближения к ним; о примирении преданий нашего прошлого с условиями настоящего и потребностям будущего.

Bсе эти и многие другие теоретические и практические вопросы имеют, так сказать, международный характер в среде греко-славянской. Они могут быть разрешены не иначе как путем взаимного и добровольного соглашения, целого ряда компромиссов между противоречивыми стремлениями и интересами отдельных славянских и неславянских народов нашей исторической системы.

\section{$\mathrm{XVI}$}

Но как, где, чем достигнуть этого соглашения? Путем ли общих съездов? Обществ? Учреждений?

Конечно, и эти средства очень важны и желательны. В доказательство сошлемся на московский Славянский съезд 1867 г., который оставил столь глубокий след если не в жизни, то, по крайней мере, в воспоминаниях всех славянских народов. Хорошо бы повторять подобные съезды каждые 3-4 года, как это водилось у древних греков на Олимпийских и других играх, служивших даже эрой для греческого летоисчисления.

Нечего и говорить, что учреждение обществ такого типа, как Gustav-Adolf Verein, Allgemeiner deutscher schulverein и т. п., также много содействовало бы духовному сближению и сплочению частей нашего племени.

Но осуществление подобных съездов, учреждение подобных обществ нередко бывает соединено с такими препятствиями, которые возможно устранить лишь после долгой и упорной борьбы с затруднениями то личными, то общественными, политическими, экономическими и т. д.

\section{$\mathrm{XVII}$}

А между тем рядом со всеми этими способами племенной и культурной организации есть еще один, который, не уступая прочим в действительности, в то же время гораздо легче может быть применяем к делу: это путь литературного обмена мыслей между братья- 
ми и культурными сподвижниками, в особенности же на страницах общего периодического издания.

Этот способ служения словом делу их нравственной организации имеет то преимущество перед прочими, что слово, как известно, является наиболее естественным посредником между чувствами и мыслями, решениями и действиями. Если бы при разработке подобного рода сложных вопросов мы избрали противоположный путь, т.е. от дела перешли бы к решению, а от последнего к выражаемому словом понятию и, наконец, чувству, то поступили бы менее согласно с законами и психологии, и истории. Не потому ли, между прочим, и высокие подвиги русских людей в 1812, 1849 и 1877- 78 гг. не принесли ожидаемых результатов, что они предприняты были без исторической подготовки, предварительного обсуждения всех сторон дела и всех подробностей предприятия?

\section{$\mathrm{XVIII}$}

Но для того чтобы еще темное поле русско-славянского сознания было освещено с точки зрения и истории, и действительности, необходимо свести в один фокус лучи самых различных воззрений, взаимно проверяемых и дополняемых общими силами и усилиями.

В этих-то видах, предприняв при содействии единомышленников издание «Славянского обозрения», мы намерены открыть его страницы писателям всех славянских или, точнее, всех греко-славянских народностей, притом различных направлений, под условием искреннего желания содействовать печатным словом уяснению того или другого вопроса в общих интересах восточнохристианской образованности. Только статьи, враждебные славянству, его историческим преданиям, стремлениям, идеалам или направленные к усилению не любви и согласия, а вражды и раздоров между членами нашего культурного мира, не найдут, конечно, места в нашем издании. Его девизом будет литургический возглас: «Возлюбим друг друга, да единомыслием исповемы»... Любовь к братьям (по крови, вере и судьбам) как основа единомыслия; единомыслие как нравственная опора личности в исповедании своих убеждений; исповедание их как начало осуществления - вот программа, по которой человек и христианин должен возвышаться от чувства к познанию, а от мысли к деятельности, в служении своим профессиональным идеям и идеалам. В верном применении и развитии славянами этой программы заключается, по нашему убеждению, единственный выход и из тех бесчисленных затруднений в их нынешнем положении, которые накопились веками и лишь незначительная часть коих намечена в настоящем очерке. 
Тем же началам служили, той же программой руководились лучшие из писателей и деятелей так называемого славянофильского направления, а между ними ныне наиболее еще памятный издатель «Дня», «Москвы», «Москвича» и «Руси» И. С. Аксаков. Но, располагая поистине богатырскими силами, Аксаков слишком, кажется, доверял им, принимая на свои плечи чуть не всю тягость издания. Мы в этом отношении не можем и не желаем следовать за ним, а, наоборот, предполагаем разделить эту тягость между возможно большим числом сотрудников. Нашей главной обязанностью как редактора будет привлечение на общий труд греко-славянских сил и, в нужном случае, примирительное между ними посредничество, чтобы таким образом содействовать своевременному уяснению выдвигаемых жизнью вопросов и разрешению их в духе основных начал восточнохристианской образованности, на благую пользу всех ее участников и деятелей.

Источник: Будилович А.С. К читателю // Славянское обозрение. Историколитературный и политический журнала. 1892. Т. 1. Январь. С. 1-18.

Source: Budilovich A.S. To the Reader. Slavic Review. Historic, Literary. Political Journal. Jan. 1892. Vol. 1. pp.1-18.

Будилович Антон Семенович (1846-1908) - русский филолог, славист, публицист, редактор, общественно-политический деятель, популяризатор славянофильских идей, профессор историко-филологического института кн. Безбородко в Нежине (1875-1881), профессор Варшавского (1881-1892) и профессор и ректор Дерптского (1892-1901) университетов, член-корреспондент Санкт-Петербургской академии наук, почетный член Санкт-Петербургской духовной академии, тайный советник. Секретарь, товарищ председателя Санкт-Петербургского отдела Славянского благотворительного комитета, основатель и председатель Галицко-русского общества.

Budilovich Anton Semenovich (1846-1908) - Russian Philologist, Slavist, Publisher, Editor, Social-Political figure,Promoter of Slavophile ideas, Professor of the HistoricPhilologic Institute in honor of Prince Bezborodko in Nezhin (1875-1881), Professor of the Warsaw University (1881-1892),Professor and Rector of Derpt University (1892-1901), Member Correspondent of the St. Petersburg Academy of Science, Honored member of the St. Petersburg Theological Academy, Secret Advisor. He was also Secretary, Colleague of the President of the St. Petersburg Branch of the Slavic Benevolent Committee, Founder and President of the Galician-Russian Society. 